\title{
COVID-19 Y DERECHOS: ¿ES POSIBLE OTRA ECONOMÍA?
}

Laura Albornoz Pollmann 


\title{
LAURA ALBORNOZ POLLMAN
}

\begin{abstract}
Abogada, Licenciada en Ciencias Jurídicas y Sociales por la Universidad de Chile, Máster en Gestión y Dirección de Recursos Humanos por la Escuela Internacional de Negocios de Madrid, Doctora en Derecho Civil e Internacional Privado por la Universidad de Sevilla, en España, Profesora Asociada de Derecho Civil en la Facultad de Derecho de la Universidad de Chile. Ministra Directora del Servicio Nacional de la Mujer entre los años 2006 y 2009.
\end{abstract}




\section{COVID-19 Y DERECHOS: ¿ES POSIBLE OTRA ECONOMÍA?}

El confinamiento y las probibiciones que lo acompañan, por temor al contagio del Covid-19, han limitado el albedrío de la ciudadanía y el ejercicio de sus derechos, y también la posibilidad de defenderlos, de una manera solo comparable con épocas dictatoriales. Pero estas limitaciones no ban tenido el mismo efecto en todos los segmentos poblacionales. No ha sido igual para los más ricos y quienes no lo son; no lo es para los pueblos originarios y quienes no están en ese grupo; no lo es para la tercera edad comparada con la gente joven ni lo es para hombres en comparación con las mujeres ni personas con otras identificaciones sexuales. Claramente, la peor parte se la han llevado las mujeres y todos quienes no entran en las estructuras patriarcales de poder.

Nos preguntamos si al terminar este periodo de privaciones de libertad impuestas para aplanar la curva de contagios del Coronavirus - un lapso de goce desigual de derechos, de discriminaciones y violencias al desnudo- seremos una sociedad diferente y quién tomará en sus manos los cambios, quién decidirá la dirección en que irán. ¿Qué herramientas podemos vislumbrar para que estos fortalezcan la democracia, una economía más inclusiva y el abanico de derechos humanos?

El país se encontraba en pleno ambiente de manifestaciones públicas contra el establishment cultural, político, económico, laboral, educacional, financiero, de seguridad social, de securitización de la salud y otros ámbitos. Quienes a partir del 18 de octubre de 2019 expresaban su descontento en plazas y avenidas — de todas las edades y diferentes grupos de interés y niveles socioeconómicos- demandaban del Estado respeto por su dignidad de personas. Las y los manifestantes, que en un momento llegaron a los siete dígitos, en marzo de 2020 se habían retirado parcialmente de las calles, a la espera de respuestas de las autoridades. Todo esto, mientras las encuestas mostraban una notable baja hasta el 9 por ciento o 6 por ciento $^{1}$ de aceptación del presidente, según distintas encuestadoras, niveles que nunca antes se habían registrado en el país ${ }^{2}$. La reacción de la élite política, tanto del Congreso Nacional como del Poder Ejecutivo, consistió en un ágil despliegue de ofertas legislativas y políticas públicas que con los días fueron perdiendo temperatura. Fue entonces que algo impensado se hizo presente en la vida nacional: la amenaza del Coronavirus. Las prioridades cambiaron de la noche a la mañana, aunque en medio de un clima de incredulidad y sospechas de diferentes tintes.

1. CEP, 2019.

2. Encuesta Plaza Pública-Cadem, 10 de febrero, 2020. 


\section{¿ES QUE LA ECONOMÍA ORTODOXA RETROCEDE UN PASO? (PENSANDO AVANZAR OTROS, CLARO)}

La crisis pandémica ha puesto en primer plano la ruptura de la relación tácita entre la administración y la ciudadanía, respondiendo del modo esperado para un modelo neoliberal, vale decir:

... ampliar el volumen de la actividad económica, disminuir los costos de la mano de obra, permitir o alentar la deslocalización de la producción (entre otras cosas, de productos médicos claves, como mascarillas y respiradores), desregular la actividad bancaria y los centros financieros y apoyar las necesidades de las corporaciones. El resultado fue, ya sea por voluntad o por omisión, una extraordinaria erosión del sector público. El segundo hecho que quedó a la vista de todos es que solo el Estado puede manejar y superar una crisis de tamaña escala (Osava, 2020, p. 1) ${ }^{3}$.

En opinión del profesor Ladislau Dowbor, especialista en convergencia de procesos críticos, el Covid-19, con sus efectos, ha sido catalizador de las fallas concomitantes del modelo, como la degradación ambiental, la desigualdad, el monopolio del capital económico y del poder político.

Políticas económicas neoliberales trataron de reducir el papel del Estado y cumplir una austeridad fiscal que limitó inversiones en los sistemas públicos de salud. Todo eso pesa ahora, los pobres están más vulnerables al Coronavirus y se redujo la capacidad de respuesta a la pandemia (...). La desigualdad, reflejada en los ingresos, en la vivienda y saneamiento precarios, hacinamiento y largos traslados en el transporte colectivo, favorece la propagación del virus y su letalidad, se comprobó en Estados Unidos y se teme confirmar con creces en América Latina y África (Dowbor, en Osava, p. 1) ${ }^{4}$.

El Coronavirus tiró ferozmente el mantel de las economías nacionales y ha estado obligando a los gobiernos, incluso a los más negacionistas, como los de México, Brasil y Estados Unidos, a optar por la salud de la gente y dejar en casa

3. Osava, Mario. Periodista de Inter Press Service, IPS. 24 de abril, 2020.

4. Profesor de posgrado de la Pontificia Universidad Católica de São Paulo, entrevistado por Mario Osava para IPS. 
a trabajadoras y trabajadores de algunas actividades económicas y resignarse a ralentizar el crecimiento.

Tienes enfrente la paralización del $80 \%$ de la economía y si despiden a todo el mundo y no le entregas ningún tipo de ingreso a esa gente, la demanda económica va a colapsar y las pocas compañías que resisten van a colapsar y finalmente toda la economía (Ja-Hoon Chang ${ }^{5}$ ).

El gobierno de Brasil abandonó temporalmente su política de austeridad fiscal y aprobó un "presupuesto de guerra" que le permite destinar una millonaria ayuda de emergencia a familias, trabajadores, municipios y empresas (Núñez, 2020) ${ }^{6}$. La administración de Estados Unidos, por su parte, anunció un paquete de dos billones de dólares, 10 por ciento del PIB, para reforzar la debilitada economía estadounidense $^{7}$, compensando pérdidas, protegiendo empresas ante la repentina pérdida de sus ingresos y, por cierto, para sostener el empleo y la demanda en el juego de la economía.

Mientras Chile, con una deuda pública menor al $30 \%$ del $\mathrm{PIB}^{8}$, plantea soluciones que representan alrededor del 5\% de este, otros países de la región, con menor capacidad de endeudamiento, hacen esfuerzos mucho más sustantivos. El Estado de Catástrofe parece haberse invocado más para recurrir a la represión que para una efectiva acción pública (Heiss, 2020, p. 2) $)^{9}$.

"Han quedado expuestas las vulnerabilidades más evidentes de cada país", dijo en reciente visita a Chile la Alta Comisionada de Naciones Unidas para los Derechos Humanos, Michelle Bachelet ${ }^{10}$, refiriéndose a las desigualdades instaladas como telón de fondo de la crisis sanitaria.

Efectivamente, han quedado en evidencia la desigualdad de género transversal y la violencia hacia las mujeres y lo femenino, pero no en forma químicamente pura.

5. Académico de la Universidad de Cambridge. En revista Pulso de La Tercera.

6. Núñez, Rogelio, investigador sénior asociado del Real Instituto Elcano, Doctor en Historia Contemporánea de América Latina por el Instituto Universitario de Investigación Ortega y Gasset de la Universidad Complutense. Director del Centro de Política Internacional Félix Varela de Madrid.

7. Revista Fortune, sección economía.

8. 27 por ciento según Cepal. 2019, p. 26.

9. Claudia Heiss es integrante de la Fundación Carolina.

10. En conversatorio por Instagram Live de Fundación Horizonte Ciudadano, 21 de mayo, 2020. 
También hay un criterio económico que secretamente necesita esta desigualdad y, por ello, la ignora. Ambas cosas, la violencia de género y el desentendimiento de la importancia y el valor económico del cuidado que realizan las mujeres, se han perfilado nítidamente en los confinamientos obligados por la pandemia. Se trata de una mirada y praxis de la economía llamada ortodoxa, que prescribe a las autoridades temer, en primer lugar, por la merma en los índices de crecimiento económico. Es así que el poder institucional sitúa sus discursos de campaña y sus cifras de infectados y muertos, que quieren ser triunfales y competitivas regionalmente, por encima del buen vivir de la ciudadanía, que ve perturbada su vida a causa de las obligaciones de prevención con cumplimiento controlado por la policía o fuerzas militares, y del desplome de las economías familiares.

El negacionismo de algunos gobernantes frente al peligro cercano de la pandemia ha sido coherente con el comportamiento de un homo economicus y de esa manera ha sido transmitido a sus conciudadanos. Es así que el país con el gobierno más capitalista y más ortodoxo en términos de modelo económico (Estados Unidos) y su símil en América del Sur (Brasil) han exhibido el mismo fenómeno: multitudes organizadas reclamando por la imposibilidad de salir a trabajar fuera de casa. Así ha ocurrido en las ciudades estadounidenses de Michigan ${ }^{11}$, con algunos manifestantes portando armas, y en Pensilvania, donde una muchedumbre con carteles fue alentada por el propio presidente Donald Trump. Una pancarta en Tennessee rezaba "sacrifiquemos a los débiles" numerosa manifestación en Sâo Paulo, con el respaldo de Jair Bolsonaro, quien además anunció un posible apoyo a esas demandas por parte del Ejército de Brasil. El conservador primer ministro Boris Johnson, de Gran Bretaña, aliado de Estados Unidos en su enfrentamiento con la Unión Europea, se había negado inicialmente a las restricciones, alegando respeto a las libertades individuales (hasta que se contagió él mismo), como ha hecho también la derecha nacionalista de España.

Curiosamente, Estados Unidos y España lideran el ranking de contagio y mortalidad por Covid-19 entre los países del llamado primer mundo, el primero con 42 mil 514 muertes y el segundo con 20 mil 852 hasta mayo de 2020; mientras que Brasil hace lo suyo en América del Sur con dos mil 587 muertes, una cifra que más que sextuplica las de Perú, país que le sigue en la lista.

Los casos mencionados corresponden a los países de los homo economicus, pero ya no a cargo de sus empresas, sino de gobiernos nacionales, con el enorme poder

11. https://www.eldiario.es/internacional/Michigan-Nunez-Balboa-manifestacionesconfinamiento_0_1027497302.html

12. Periodista Chacour Koop en el Miami Herald. 
que esto les confiere. En estos casos, vemos magnificadas sus características. Si consideramos el fracaso de las políticas de Donald Trump en Estados Unidos y Sebastián Piñera en Chile, con la consiguiente baja de aprobación popular cerca de periodos eleccionarios, se entiende que, desde sus intereses, deben jugarse por evitar una recesión económica. Con habilidades como financistas, pero presentados como empresarios en sus campañas electorales, tienen en esta última definición sus principales banderas y apuestan por la menor merma posible en el crecimiento económico de sus países a costa de arriesgar la salud de la población, vale decir, ignorando un entorno humano en que "lo peor está por venir", como ha dicho Tedros Adhanom Ghebreyesus, director general de la Organización Mundial de la Salud.

Ambos mandatarios representan el capital financiero especulativo y no la creación industrial; sus convicciones calzan con estas motivaciones y razonamientos:

Desde mediados del siglo XIX, la Economía se ha basado en el supuesto de que los agentes económicos toman decisiones racionales, maximizando su utilidad o bienestar de acuerdo a sus propias preferencias (estables) e intereses. El orden económico resultante de esa pluralidad de decisiones es considerado óptimo o eficiente... Con este supuesto central se ha construido una teoría microeconómica (para personas, hogares, empresas) y luego se ha usado para darle micro fundamentos a la teoría macroeconómica (Maletta, 2010, p. 10) ${ }^{13}$.

\section{LA ECONOMÍA FEMINISTA}

El término empezó a ser usado a principios de los noventa, pero el análisis económico de las desigualdades de género había aparecido largo tiempo antes. "Por ejemplo, las brechas salariales entre hombres y mujeres fue un tema que ya se debatió en 1918 y de nuevo en 1936 en Inglaterra, y el debate sobre el trabajo doméstico en Europa, durante la década de 1970". Los modelos en boga "no cuestionaban las normas patriarcales y relaciones de género que ponen a las mujeres en condiciones de subordinación y de opresión: formas patriarcales de dominación/subordinación como sistemas de propiedad y de herencia" (Benería, 2020) ${ }^{14}$.

13. Héctor Maletta es miembro del Instituto de Investigación en Ciencias Sociales de la Universidad del Salvador en Buenos Aires, Argentina.

14. Lourdes Benería es catedrática emérita de la Universidad de Cornell. 
Sabemos que las relaciones de poder nunca son neutrales desde el punto de vista del género y que tampoco lo son respecto de los sectores que la institucionalidad estatal desea marginar. En el sistema económico actual de casi todos los países está muy bien "distribuida" la discriminación por género; pocas mujeres en cargos de jefatura bajo un techo de cristal que alimenta el escaso acceso a las capacitaciones. A ello se agrega una resistente brecha salarial. Luego, vemos que las mujeres son las más afectadas por la pobreza, por la merma de sus propios ingresos, los despidos de los demás miembros de la familia, las violencias y las normas de cuidado obligadas a causa del Coronavirus, ya sean preventivas o exigidas debido a un familiar o allegado ya afectado por el virus. Dentro del segmento de las mujeres, y haciendo una mirada interseccional, vemos que a quienes más se les dificulta la vida en el periodo de crisis es a las mujeres mapuche, las inmigrantes, las que pertenecen a los quintiles de ingreso más pobres, las que sufren alguna discapacidad, las mujeres confinadas.

Entre quienes adoptan la informalidad como estrategia de sobrevivencia se concentra un gran porcentaje de mujeres, "entonces la crisis y el desempleo en particular va a tener un impacto mucho mayor en las mujeres que en los hombres en términos del tipo de trabajo que realizan", dice Claudia Mora ${ }^{15}$.

"La tasa de desempleo a nivel país es 7,8 por ciento según el último dato del INE, pero si nos vamos al 10 por ciento con menor ingreso el desempleo es 29 por ciento; si nos vamos al 10 por ciento de mayores ingresos, el desempleo es 2 por ciento", manifiesta el economista David Bravo y agrega que el estado de salud es peor también entre los más pobres, con un 48 por ciento de "condición previa como diabetes, cáncer, enfermedad coronaria, etc.", mientras los del 10 por ciento de mayores ingresos muestran solo un 31 por ciento de prevalencia de dichas afecciones ${ }^{16}$.

La economía feminista profundizó teórica y empíricamente en los orígenes y efectos de las distintas desigualdades de género y su conexión con la economía. "El género está en todas partes" escribió la historiadora norteamericana Joan Scott ${ }^{17}$, del mismo modo que la categoría clase está en todas partes (Benería, 2020).

15. Doctora en Sociología de la Universidad Mayor. En: https://www.emol.com/noticias/ Economia/2020/04/29/984525/Desempleo-crisis-repercusiones-riesgo-Chile.html

16. Economista experto en materia laboral y director del Centro de Encuestas y Estudios Longitudinales de la PUC. Entrevistado en : https://www.emol.com/noticias/Economia /2020/04/29/984525/Desempleo-crisis-repercusiones-riesgo-Chile.html

17. Historiadora estadounidense especializada en historia de las mentalidades, con importantes contribuciones en el campo de la historia de género, historia de la mujer e historia intelectual. Es titular de la cátedra Harols F. Linder en la Universidad de Princeton, Nueva Jersey, Estados Unidos. 
La economía feminista plantea - pues es posible y necesario- que toda la economía puede analizarse desde un punto de vista feminista. Fue a principios de la década de 1990 cuando se afianzó la expresión, especialmente con la creación de la International Association for Feminist Economics (Iaffe) en EE.UU. Desde entonces, la economía feminista se ha extendido en todas direcciones, incluyendo España. Esta corriente critica la economía ortodoxa, "tan conectada al capitalismo neoliberal. La economía de los cuidados centra buena parte de la visibilización de las desigualdades de género" (Benería, op. cit.)

Al mismo tiempo, la teoría ortodoxa concede una importancia primordial al crecimiento económico y al aumento del consumo y la inversión sin considerar sus efectos, por ejemplo, sobre el medio ambiente y la sostenibilidad del planeta y de las generaciones futuras. Esto lleva al correspondiente consumismo y economismo o a la preponderancia de lo económico en la vida social y política, como hemos visto tan claramente durante el periodo neoliberal. Desde la economía feminista, otro aspecto básico es la necesidad de transcender el androcentrismo del hombre económico y su visión economicista de lo social y político (Benería, op. cit.).

No es, pues, de extrañar que un tercer aspecto de la economía feminista sea la construcción de una visión alternativa de la economía, empezando por la pregunta sobre qué es la propia economía y cuál es su objetivo. Revisando los distintos escritos y debates que han aparecido al respecto, surge una primera aproximación a la respuesta en el sentido de que no se trata de la maximización de los beneficios del capital o de la ganancia individual o del crecimiento económico o del consumismo, sino de la construcción del bienestar social para todas las personas, o sea, del bien común (Benería, op. cit.).

En términos de sustentabilidad, la economía feminista se relaciona cada vez más con el ecologismo. El abuso y menoscabo del medio ambiente, con el consecuente cambio climático, más el consumismo y el despilfarro agregado son antagónicos con la economía feminista y el modo de ver el mundo de las mujeres; el trabajo de cuidado de personas dependientes y de otras que las subordinan y les exigen ser "atendidas" las tiene permanentemente en contacto y empatía con las necesidades del planeta Tierra, que vienen a ser las mismas nuestras. Desde el modelo económico hegemónico esto se vislumbra de otra manera, más depredadora y egoísta, que nos lleva nuevamente a las características del homo economicus. La crisis del Coronavirus, a modo de ejemplo, ha develado para los más incrédulos e indiferentes que el extractivismo y, en general, la mercantilización de los recursos naturales nos ha privado del agua en más de un territorio del país. Sin agua es casi imposible entrar a la campaña de "Lávese las manos repetidamente entre 20 y 40 segundos". 


\section{SOBRE EL TRABAJO REALIZADO EN EL HOGAR}

Los estudios sociales han demostrado la estrecha conexión entre capitalismo, subvaloración del trabajo del hogar y devaluación de la posición social de las mujeres. Estos estudios han mostrado que el modelo patriarcal de familia, que controla la sexualidad y la procreación, "ha sido funcional no sólo para la perpetuación del patriarcado sino también para el establecimiento y expansión del modelo capitalista" (Zúñiga, 2018) ${ }^{18}$.

El trabajo doméstico ha sido impuesto a las mujeres como si fuera un atributo natural, una expresión del instinto maternal. Al fundirse con la concepción social de la feminidad y definirse por oposición al trabajo de mercado, ha logrado transformarse en un no trabajo o, en el mejor de los casos, en una actividad que no es susceptible de la retribución típica de una transacción mercantil. Así, los bienes que las mujeres elaboran y suministran al interior del hogar (alimentación, aseo, cuidado, educación, contención emocional, etc.) son simbolizados como un producto del amor y deben, congruentemente, ser recompensados únicamente con este.

Llamarle "labores" al trabajo doméstico ha reforzado la creencia de que no se trata per se de un trabajo. Negarle valor al trabajo reproductivo ha permitido velar su enorme contribución política y económica. La producción y reproducción de la fuerza de trabajo - vitales para el mercado- han sido posibles gracias a la gestión de cuidado de niños/niñas, ancianos y otras personas dependientes, que realizan las mujeres en los hogares, de manera gratuita (Zúñiga, op. cit.).

La colocación en el mercado del trabajo doméstico ha tenido la ventaja de hacer notar su valor económico. Con todo, la sustitución del trabajo doméstico por los servicios externos de limpieza y/o cuidado "tiene muy poco de subversivo desde el punto de vista de género”. Las labores que algunas mujeres dejan de realizar en el hogar "con motivo de su inserción en el mundo laboral, no son realizadas, tampoco, por sus novios, maridos o convivientes" (Zúñiga, op. cit.).

El trabajo doméstico y de cuidado, al no ser remunerado para las mujeres por no estar industrializado y, por tanto, no ser considerado parte de la economía por no transarse en el mercado, ha sido protagonista en todos los escenarios familiares desde que sonó la alarma de pandemia. Estas mujeres, según la economía ortodoxa,

18. Yanira Zúñiga Añazco es Doctora en Derecho por la Universidad Carlos III de Madrid, profesora de la Facultad de Ciencias Jurídicas y Sociales de la Universidad Austral de Chile, Valdivia, Chile. 
no forman parte de la PEA $^{19}{ }^{20}$ femenina, a pesar de los ya numerosos estudios sobre el uso del tiempo desagregado por sexo. Se trata de una cuestión que debe cambiar si queremos políticas públicas adecuadas que proporcionen bienestar a la población.

Fronteras morales: un argumento político para una ética del cuidado es el libro publicado en 1993 por la pensadora estadounidense Joan Tronto ${ }^{21}$. "Se trata de cuidar el mundo, y a nosotros como parte de él", apunta, y se pregunta por qué los que realizan estos trabajos esenciales son más mal pagados y por qué, en su mayoría, quienes los ejecutan son mujeres, personas pobres o afrodescendientes. "Eso significa que nuestros valores están distorsionados. No solo las personas, sino todas las cosas, los animales, las plantas, el mundo mismo, necesitan cuidados", dice, y agrega que no todas las formas de cuidado son buenas, pues "también es posible cuidar mal. Y esta pandemia ha expuesto que la salud pública (...) la atención o el cuidado público siguen siendo vitales para que la sociedad prospere".

\section{LA VIOLENCIA MACHISTA EN EL CONFINAMIENTO}

Todos los Estados deben hacer esfuerzos significativos para abordar la amenaza Covid-19, pero no deben dejar atrás a las mujeres y los niños y niñas víctimas de violencia doméstica, ya que esto podría conducir a un aumento de la violencia doméstica, incluyendo los feminicidios (Simonovic, 202022).

Fue lo que dijo Duvravka Simonovic, relatora especial sobre la violencia contra la mujer, sus causas y consecuencias. Y añadió que el riesgo es mayor cuando en un momento de crisis

no hay o quedan menos refugios y servicios de ayuda disponibles para las víctimas; cuando es difícil acceder a aquellos que aún están abiertos; y cuando hay menos apoyo de la comunidad; menos intervenciones policiales y menos acceso a la justicia porque muchos tribunales están cerrados (Simonovic, 2020).

19. Población económicamente activa.

20. Silva Monge, M. 2020. "Industria de servicios familiares vs. 'labores de hogar"'. En: www. circuloabierto.cl . Consultada el 22 de abril de 2020.

21. Entrevistada en diario El Mercurio, 3 de mayo de 2020.

22. Declaración de la relatora especial sobre la violencia contra la mujer de la ONU, Duvravka Simonovic, 27 de marzo de 2020. 
"Para empeorar las cosas, las restricciones de movimiento, las restricciones financieras y la incertidumbre generalizada estimulan a los perpetradores y les proporcionan poder y controles adicionales". Simonovic expresó su especial preocupación por las mujeres con mayor riesgo de violencia doméstica, como las que viven con alguna discapacidad, las indocumentadas y las víctimas de la trata: "Los gobiernos no deben permitir que las circunstancias extraordinarias y las medidas restrictivas contra el Covid-19 conduzcan a la violación del derecho de las mujeres a una vida libre de violencia".

Estas declaraciones fueron respaldadas por Alda Facio, Elizabeth Broderick y Maria Grazia Giammarinaro, relatora especial sobre la trata de personas, especialmente mujeres y niños.

La mitad de las denuncias por violencia doméstica con respecto a un periodo normal es lo que alerta el Centro de Medidas Cautelares de Santiago ${ }^{23}$. También la Fiscalía registra una baja de 18 por ciento a nivel país desde que se dio inicio al Estado de Excepción decretado el 20 de marzo de 2020. Las causas pueden ser muchas y aún falta estudiar más la situación. "Hay un aislamiento que mantiene a la víctima fuera de la red que podría brindarle ayuda", dice la magistrada Jessica Arenas, coordinadora del Centro. Por su parte, la abogada Marianela Villarroel, consejera de la Fundación Pro Bono, cree que estos porcentajes no significan que haya menos agresiones y que, "por el contrario, la mayoría de alcaldes han acusado un aumento consultas y situaciones" de violencia. Además, añade, "muchas familias han quedado con un solo proveedor, generalmente el agresor, y la víctima prefiere no denunciar" a fin de no poner en riesgo ese ingreso.

La jueza Arenas también teme que haya mujeres con miedo de que "las saquen de su hogar con sus hijos o hijas para llevarlas a una casa de acogida, mientras el agresor permanece en el hogar común".

No debemos olvidar que la gestión de conflictos puede tornarse violenta por efectos del encierro, restricción de relaciones sociales y familiares, y el molesto telecontrol laboral (se suprime la charla entre compañeros, los minutos en el sanitario, la ingesta de café, etc.), el exceso de información (sobre contagios, muertes y gestión de cadáveres), que producen estado emocional colectivo de inseguridad y detonan la expresión de la cultura machista aún prevaleciente en la sociedad.

El temor al contagio o a la pérdida del empleo, el cumplimiento vigilado de medidas de protección del virus y episodios difíciles con los niños y niñas de menor edad, como crisis de salud, pataletas, mascotas encerradas, etc., pueden gatillar las conductas violentas de los hombres que suelen tener regulado su machismo.

23. Diario El Mercurio, 20 de abril de 2020. 


\section{EL TELETRABAJO Y LAS MUJERES EN ESTA CRISIS}

La crisis del Coronavirus ha confinado a millones de personas en sus casas, obligando a muchas de ellas a sacar adelante su trabajo de forma remota y vigilada, a la vez que cuidan de sus hijos u otros familiares vulnerables. Si nos referimos a las mujeres que no han perdido sus empleos durante la crisis económica-sanitaria podemos observar que el teletrabajo instaurado en el periodo ha significado dobles o triples funciones para ellas en la mayoría de los casos.

El mensaje del \#CuidémonosEntreTodos, siendo el cuidado una actividad económica fundamental, desplaza la responsabilidad pública del Estado en una circunstancia crítica como la actual y la traspasa a la población, es decir, a las mujeres, que deben asumirla como un trabajo sin retribución que se agrega a la situación ya dificultosa y precaria en los hogares, originada a partir de la crisis o previamente. Todo esto, incluso en el supuesto de que no existan situaciones de violencia machista.

Se dan diversas situaciones. Las mujeres que realizan teletrabajo y tienen pareja, también con teletrabajo, viviendo en el mismo hogar, suelen hacerse cargo de más acciones de cuidado que el hombre o los hombres.

La mujer es la que en varios casos debe ceder su computador a los hijos o hijas para que puedan asistir a sus clases virtuales, lo que implica que también ella es la que asume el refuerzo escolar. El varón cree que es lo justo, ya que él tiene un salario superior.

Respecto a las mujeres que realizan trabajo remunerado en casa y son jefas únicas del hogar, se puede observar que se repiten las circunstancias anteriores, pero no desarrollan un sentimiento de injusticia con respecto a una pareja.

Por otro lado, las mujeres que no han podido trabajar remuneradamente y tienen una pareja sin trabajo viviendo en el mismo hogar, casadas o no, son las que tienen más posibilidades de compartir cuidado y trabajo doméstico a través de la planificación de actividades productivas comerciales compartidas.

Las mujeres que realizan teletrabajo y tienen pareja cesante viviendo en el mismo hogar deben sufrir la victimización de la pareja sin trabajo, quien las recrimina por "la suerte" que ellas han tenido. El hombre casi no hace su parte de trabajo doméstico, pero se hace cargo de algunas actividades de la prole.

\section{DERECHOS DE LAS PERSONAS CONFINADAS}

Aparte del derecho a la vida y la integridad física y psicológica de las personas, más transgredido entre las mujeres, niñas y niños, hay muchas situaciones en que estos son vulnerados, especialmente en condiciones de confinamiento y crisis económica. 
Por ejemplo, a las personas de mayor edad se les "aconseja" no salir de sus hogares, aunque no estén en comunas en cuarentena. Muchos sospechan que lo que se quiere evitar no es que enfermen, sino que no ocupen equipos y esfuerzos médicos que puedan usar personas contagiadas más jóvenes. Profusión de cartas a los diarios muestran la inquietud de la cuarta edad, que teme sentirse presionada a renunciar a sus posibilidades y derecho a la atención de salud. La ONU ha hecho un llamado a mejorar la protección de personas mayores, pues todas las personas tienen derecho a acceder a intervenciones que les salven la vida ${ }^{24}$.

Por otra parte, el personal médico, de enfermería y auxiliares se encuentra desprotegido y los noticieros nos han mostrado casos de contagios en madres funcionarias de centros de salud que han infectado a sus familiares. No se han implementado servicios de cuidado para las hijas o hijos que se encuentran en esos hogares. Tampoco ha habido rigurosidad en la entrega de implementos de seguridad para este personal, lo que ha puesto en riesgo su derecho a la salud y la vida.

También está en riesgo el derecho al agua potable, crucial en época de prevención de contagio.

Además, el Estado debe intervenir a favor de la población de inmigrantes, especialmente en los casos de personas negras, cada vez que sean discriminadas o perseguidas. La no intervención puede considerarse una violación de derechos humanos.

En una situación de crisis económica-sanitaria y confinamientos, las personas que viven con discapacidades como ceguera, sordera, alguna parálisis o alguna circunstancia similar, quedan especialmente vulnerables al maltrato u otra victimización.

Mientras, en otra dimensión, se discute sobre los derechos humanos, si acaso hay derechos sin deberes, si ambas cosas van por carriles distintos, si el disfrutar de un derecho es una cuestión absoluta o si el único deber es el de respetar los derechos humanos.

Se deben proteger los derechos a la salud y la vida de las personas privadas de libertad. Si bien el problema de la falta de seguridad dificulta estas acciones, tenemos una lección por delante: hay que preocuparse de la población carcelaria - y en esto el Estado no ha sido eficiente- pues no ha dejado de estar conformada por personas titulares de derechos. Estos mejoramientos también favorecerían a los funcionarios de Gendarmería y otros.

El derecho a la libre circulación de información debe ser protegido durante la pandemia. La vivienda, por otra parte, "es la primera línea de defensa contra el

24. Acnudh.org. 
brote del Covid-19", nos urge Naciones Unidas. De igual modo, los órganos de derechos humanos de la ONU piden no descuidar este enfoque en la lucha contra la pandemia.

Por último, es importante que los gobiernos no abusen de medidas de emergencia que redunden en estrechar el goce de derechos humanos de la población. Por el contrario, los derechos humanos deben estar al centro de la respuesta al Covid-19.

El secretario general de Naciones Unidas, Antonio Guterres, señaló que "en el actual contexto de crisis, donde crecen el nacionalismo, el populismo y el autoritarismo, algunos países pueden utilizarlo como excusa para adoptar medidas represivas con fines no relacionados con la pandemia (...). La amenaza es el virus, no las personas" 25 .

\section{SITUACIONES FAMILIARES COMPLEJAS Y CONFINAMIENTO EN LOS HOGARES}

Con respecto a la salud mental, sabemos que hay familias que cuentan entre sus miembros a personas con discapacidad psíquica que origina en ellas alteraciones del ánimo, conductuales o similares. Algunas de estas han estado siempre en su hogar a cargo de una cuidadora externa, una persona del mismo grupo familiar o bien en un establecimiento de salud mental de internación de larga estadía o en un hospital de día.

Por otra parte, es sabido que la confirmación del contagio con Coronavirus puede despertar ideas suicidas en algunas personas. Por tal motivo, es relevante que esta noticia se entregue de manera adecuada y que, a la vez, contemple apoyo sicológico para los pacientes ${ }^{26}$.

Respecto a las personas de mayor edad físicamente dependientes, la situación de cuidado se dificulta en condiciones de confinamiento, pues desaparece el trabajo de cuidado externo pagado o desempeñado por personas de algún voluntariado, ya sea a domicilio o en un centro especializado. Estos centros son de un alto potencial de contagio y especialmente peligrosos para individuos vulnerables a la infección virológica, como las personas de edad adulta y con historial patológico concomitante al virus. Esto ha llevado, en gran número de casos, a la recuperación en los hogares de familiares de personas que originalmente estaban en casas de acogida.

25. En: https://acnudh.org/antonio-guterres-derechos-humanos-deben-estar-al-centro-de-larespuesta-a-covid-19/

26. Así lo ha señalado el psiquiatra chileno Alberto Larraín. 
El hecho de que las mascotas ya no cuenten con el espacio físico acostumbrado o se vean alteradas por el permanente aforo doméstico puede llevar al maltrato animal en presencia de niños y niñas, lo que provoca situaciones de angustia que en ocasiones desatan espirales de conducta abiertamente violentas.

Casos graves los constituyen las personas alcohólicas-problema o drogadictas en el núcleo familiar, que alteran la convivencia, especialmente en periodos de deprivación de su consumo por falta de proveedores o de dinero para contactarlos o en estados de euforia agresiva. Además, las casas o departamentos pequeños con aforo doméstico sobrepasado provocan ansiedad y molestias en la convivencia.

Situaciones muy graves son las que han debido protagonizar mujeres con embarazos no deseados por ellas y/o sus parejas, que se han visto en la necesidad de practicar interrupción del embarazo sin posibilidad de resolver los requerimientos de esa situación.

La convivencia obligada de mujeres, niñas o niños con agentes de abuso doméstico es una situación que hasta ahora no está siendo registrada institucionalmente y que no ha sido denunciada en los medios, ni siquiera contemplando las normativas éticas de estos y sus periodistas. Esto es particularmente grave, pues si se comprende que todas las violencias son psicológicas ${ }^{27}$, en el confinamiento hay espacio propicio para las distintas expresiones de abuso en contra de mujeres, niñas, niños y personas de mayor edad, en especial si su nivel de dependencia es alto y significa un trabajo de cuidado con dedicación estimada excesiva por la familia. En otras palabras, hay lugar para la violencia psicológica propiamente tal, violencia psicofísica, físicapsicosexual, psico-económica u otra.

\section{FINALMENTE...}

El Covid-19 es una prueba para las sociedades, los gobiernos, las comunidades y las personas.

El respeto de los derechos humanos en todo ámbito, incluidos los derechos económicos y sociales, y los derechos civiles y políticos, será fundamental para el éxito de la respuesta de salud pública a esta pandemia.

La administración actual vive la tensión entre evitar impopulares cifras de muertes y obtener beneficios políticos y económicos (Carrasco ${ }^{28}$, 2011), a pesar de que el bienestar y no el PIB debería ser la vara para medir el funcionamiento

\footnotetext{
27. Silva Monge, M. (1995).
}

28. Cristina Carrasco es investigadora en economía feminista y profesora de Teoría Económica de la Facultad de Economía y Empresa de la Universidad de Barcelona. 
económico, el objetivo del homo economicus es la obtención de beneficio. La economía ortodoxa está pensada para funcionar más rápido, ser más productivos y tener más beneficios, no importa quién se los lleve (Carrasco, op. cit.).

Reforzar el Estado y la salud pública para el futuro aparece como una consecuencia lógica de esa crisis. Las pandemias quedarán como amenaza permanente, aun si no vuelven a ocurrir.

La esperanza de muchas personas es que la tragedia de la pandemia, cuya dimensión aún es incalculable, conmoverá a la humanidad al punto de reducir el consumismo, impulsar soluciones para la crisis climática y para la desigualdad ahora considerada inaceptable. Pero no aparecen fuerzas políticas o sociales que aseguren decisiones favorables a tales cambios en el futuro.

Solo sociedades en que se abra espacio a una ciudadanía fuerte, articulada según sus intereses genuinos, con participación de sectores excluidos como las mujeres, diversidad sexual y pueblos originarios, que sea capaz de fiscalizar al poder y armada con medios de comunicación independientes del poder político, financiero y empresarial serán capaces de mostrarle al homo economicus que ya no tiene un lugar, especialmente si quiere ocupar las casas de gobierno de las naciones. 


\section{REFERENCIAS}

Benería, Lourdes (2020). ¿Qué es la economía feminista? En: https:// alternativaseconomicas.coop/articulo/que-es-la-economia-feminista

Carrasco, Cristina (2011). La economía del cuidado: planteamiento actual y desafíos pendientes. En: Revista de Economía Crítica, No 11. Barcelona: Unab.

García, Beatriz (2020). Diario de una madre confinada y sus amigas. En: www. circuloabierto.cl

Heiss, Claudia (2020). Chile: entre el estallido social y la pandemia. Santiago: Fundación Carolina.

Maletta, Héctor (2010). La evolución del homo economicus: problemas del marco de decisión racional en Economía. En Economía, vol. XXXIII, Nº5, Pp.1055. Buenos Aires: IICS.

Silva Monge, M. (1995). Todas las violencias son psicológicas. Documento de trabajo. Santiago: Sernam, p. 2.

Zúñiga, Yanira (2018). Cuerpo, género y derecho. En Ius et Praxis, vol, 24. N³. Talca, pp. 221-249.

\section{Medios de comunicación}

Osava, Mario (2020). ¿La pandemia podría gestar una economía menos excluyente? En: http://www.ipsnoticias.net/2020/04/la-pandemia-podria-gestar-unaeconomia-menos-excluyente-la-pandemia-la-covid-19-acentuo-las-crisismundiales-ya-visibles-reconocimiento-una-economia-disfuncionale-imp $/$ ?utm_source $=$ Spanish + - + Mejor + de + la + Semana\&utm_ campaign=1692d492e1-EMAIL_CAMPAIGN_2020_04_24_05_37\&utm_ medium=email\&utm_term=0_b685ec7ed3-1692d492e1-53076.97. Consultado el 24 de abril de 2020.

Guerrero, Francisca (2020). La prioridad debe ser proveer de ingresos a la población. Entrevista a Ha-Joon Chang. Revista Pulso. https://www.latercera.com/ pulso/noticia/ha-joon-chang-academico-de-cambridge-la-prioridaddebe-ser-proveer-de-ingresos-a-la-poblacion-de-manera-que-puedansobrevivir/3LR6ARORDVE3NB5GBUOENUN4UA/ Consultado el 27 de abril de 2020 . 
Larraín, Alberto. En entrevista en radio Cooperativa del 4 de mayo de 2020: https://www.cooperativa.cl/noticias/sociedad/salud/coronavirus/siquiatra -advierte-que-la-confirmacion-del-contagio-puede-acarrear-ideas/2020 $-05-04 / 130718 . h t m l$

Consultado el 29 de abril de 2020.

Koop, Chacour (2020). 'Sacrifice the weak' and 'Give me liberty': signs at coronavirus protests across US. En: https://www.miamiherald.com/news/coronavirus/ article242182796.html

Wingrove, J., Litvan, L. \& Steven. D. (2020). Trump and Senate agree on \$2 trillion rescue deal that includes cash handouts and stock buyback ban. En:

https:// fortune.com/2020/03/25/trump-senate-trillion-rescue-deal-cashhandouts-stock-buyback-ban/

Pérez, Andrea (2016). La economía feminista va más allá de la igualdad entre hombres y mujeres. Entrevista a Cristina Carrasco. En: https://www.eldiario. es/catalunya/economia/Cristina_Carrasco-igualdad-capitalismo-economia_ feminista_0_541396500.html 